process (waiting times in clinics, liaison at discharge, quality of explanation to patients, etc), but we hope to extend our approach to include both our performance and health outcomes.

The information generated by monitoring services complements the canvassing of general practitioners' opinions of services advocated by Hicks and Baker. ${ }^{1}$ It will provide a measure of quality in service agreements, without which price will tend to dominate the purchase of care.

\section{Provision for all}

Current legislation obliges directors of public health to define health needs and advise the district health authority. Yet the authorities' power to purchase adequate services for the whole population is likely to be increasingly weakened. Fundholders do not have to follow public health directors' advice and could even discriminate against vulnerable and high cost patients.

Fundholding practices have shown their capacity to promote imaginative change in service development. But they are small economic units; if they proliferate their novelty will diminish and with it their power to improve quality and promote innovation. This same proliferation will undermine the capacity of district health authorities to develop planned health care.

How then can a planned approach to public health be safeguarded? The best use of resources is likely when valid and independent measures of quality inform a purchaser, who is specifically charged with overall provision of health care. Monitoring quality in groups of non-fundholding practices is one way of achieving this aim. We believe it has the following advantages. Firstly, assessments of quality of service as perceived by both patients and general practitioners will be independent of both purchaser and provider, reducing the conflicts of interest of purchasers (more care versus better care) and the likelihood of cartels among providers. Secondly, with certain safeguards the information gathered can be generalised to all nonfundholding practices in a district. Thus information from a few practices can inform the service agreements for all non-fundholders in a district. Thirdly, the ability of directors of public health to discharge their obligations to all residents is enhanced. And, lastly, a powerful and skilled central purchasing agency allows general practitioners to concentrate on medicine without the hassle, additional costs, and ethical dilemmas incurred by fundholding.

District health authorities are the logical purchasers of health care, although it is likely that family health services authorities will have an increasing role. Large independent groupings of non-fundholding practices are the logical quality control mechanism for the internal market. The resulting alliance will be built on mutual respect and need. We believe it will be sustainable, powerful, and in the public interest.

We thank everyone in Towards Coordinated Practice and the department of general practice for their help. The views expressed are our own.

1 Hicks NR, Baker IA. General practitioners' opinions about health services available to their patients. BMf 1991;302:991-3.

(Accepted 4 fune 1991)

\title{
Variations in budgets of fundholding practices
}

\author{
Patricia Day, Rudolf Klein
}

Among all the changes that have recently occurred in the NHS, the introduction of fundholding has perhaps the most important long term implication. If fundholding was taken up by most practices, there would be a massive transfer of spending power from district health authorities to general practitioners. The role of general practitioners in controlling the use of NHS resources would be greatly enhanced; conversely, the ability of health authorities to determine the pattern of services would be diminished. It will be a long time before the experiment can be evaluated in terms of its impact on patient care. But the first wave provides some clues about the financial implications for the fundholders and for the NHS. Who has got how much? What are the patterns of allocation to individual fundholders? What transfer of resources is involved? And what are the issues raised by the process of determining the budgets?

To answer these questions we asked regional health authorities about the budgets of fundholding practices; 12 out of 14 provided information. In all we collected data on more than $80 \%$ of the first wave of fundholders (251 practices) with a patient population of over $3 \cdot 1$ million. In all cases, the information came in a form that made it impossible to identify the practices concerned. Further, in our analysis we have anonymised the regions and avoided any details that might have provided a clue about their identity.

\section{Pattern of spending}

Table I shows the budgets of each region and the range of allocations to individual practices. Purchasing power of $£ 207 \mathrm{~m}$ for hospital services has been transferred from the health authorities to general practitioners in the 12 regions. This would imply a total of about $£ 250 \mathrm{~m}$ for the country as a whole. By extrapolation on the basis of the proportion of the population covered if all general practitioners were to become fundholders about $£ 3200 \mathrm{~m}$ would be transferred - about $20 \%$ of the NHS hospital and community services budget for England. Although this is unlikely to occur, the calculation emphasises the potential challenge to the distribution of resources (and power) in the NHS posed by fundholding and the importance of the way in which allocations to individual practices are made.

The budget for hospital services allocated to individual practices varies from $£ 261000$ to $£ 1883000$ (table I). If the allocations for staff and drugs are added to this, the range in total practice budgets is $£ 550000$ to $£ 3400000$. These figures, however, do not account for practice size. The smallest practice in the survey had 6000 patients (less than the official threshold for fundholding), the largest 31500; this represents a fivefold variation compared with the sixfold variation in the budgets for hospital services. Of the 251 fundholders covered by our survey, $43 \%$ had fewer than 11000 patients, $49 \%$ had $11000-16000$, and $9 \%$ had more than 16000 . Of the 108 practices with less than 11000 patients (less than the original threshold), 12 had less than 9000 patients (the revised threshold). The crude budget figures therefore show only the range in the organisational and financial challenges faced by fundholders: managing a $£ 3.4 \mathrm{~m}$ a year business is clearly different from running one with a turnover of $£ 0.5 \mathrm{~m}$.
Ms Day.

BMf 1991;303:168-70

BMJ VOLUME 303 
To control for differences in practice size, table II gives the allocations per patient. This immediately, and predictably, reduces the variation. Hospital costs range from $£ 30$ to $£ 104$ per patient, both extremes being found in the same region. This region also had the widest range in spending on drugs and staff per patient and thus in the total budgetary allocation. When this region was excluded, the range became somewhat narrower and diminished further when all three elements of the budget were added together. As a rough generalisation, taking the country as a whole, the highest spending fundholders have twice as much to spend on each patient for hospital services than their more parsimonious colleagues. Though this variation is much less than the crude budgetary figures might suggest, it still leaves much to be explored and explained.

\section{Interpreting the differences}

Some people might be surprised that the differences in spending are not bigger. Studies of referral patterns have shown much larger variations. ${ }^{1+}$ However, the first wave of fundholding practices were not only self selected but were screened by the regional health authorities. As they satisfied the criteria of the regions they might be expected to be reasonably homogeneous "good" practices - that is, good in the sense of being well organised practices with adequate information systems and a corporate sense of their aims, which are the kind of tests used by the regions to screen prospective fundholders. If wide differences remain even among such practices how then is this to be interpreted?

In trying to make sense of the variations, the best starting point is the methods used by the regions to determine the hospital services budgets. Essentially, these budgets represent the product of a simple equation: existing rates of activity $\times$ the cost of those activities (that is, the prices charged by hospitals). Differences in budgets may therefore represent variations either in rates of activity, or in the prices charged by hospitals, or both.
Regions differed in the way in which they dealt with both sides of the equation. They used a variety of methods to calculate existing rates of activity (one of the problems was that information about referrals mostly did not exist and had to be collected specially). Perhaps more importantly, they pursued different strategies when dealing with hospitals: some accepted hospital prices without much argument, even though they knew that these prices might be based on extremely questionable data, while others challenged and haggled. The regions also differed in their negotiating tactics with prospective fundholders: the final budgets were the product of a bargaining process, and some regions were tougher bargainers than others. The only safe conclusion therefore is that no one explanation is likely to fit the observed differences, and in most cases there will be a complex relation between the activity and hospital prices.

Another problem is the meaning of differences in rates of activity. It is well known that health and social services costs are strongly related to age: nationally, the cost per patient is $£ 1995$ a year for those aged over 85 but only $£ 193$ a year for those aged $45-64 .^{5}$ The age composition of practice populations is therefore crucial if spending variations are to be correctly interpreted. This conclusion is reinforced by the experience of one region, which carried out a simulation exercise to calculate fundholding budgets on the basis of regional patterns of activity and costs adjusted for the age composition of the practices concerned. This turned out to be a remarkably successful predictor of the budgets finally agreed on and explained much of the variation among fundholders. Rates of activity would also be influenced by morbidity patterns within any given practice population, and these vary both between and within regions.

If the characteristics of the patient population determine cost then the various elements in the total budget - hospital costs, drugs, and staff-might be expected to be strongly related - that is, the older (or sicker) the population the greater the total demand for services and treatment. Accordingly, we examined the relation between these three elements in all the 251

TABLE I - Purchasing power of fundholding practices by region

\begin{tabular}{|c|c|c|c|c|c|c|c|c|c|}
\hline \multirow[b]{3}{*}{ Region } & \multirow{3}{*}{$\begin{array}{c}\text { Total regional } \\
\text { spending on } \\
\text { hospital services } \\
(£ \mathrm{~m})\end{array}$} & \multicolumn{8}{|c|}{ Allocation to individual practices ( $£ 000)$} \\
\hline & & \multicolumn{2}{|c|}{ Hospital services } & \multicolumn{2}{|c|}{ Prescribing } & \multicolumn{2}{|c|}{ Staff } & \multicolumn{2}{|c|}{ Total budget } \\
\hline & & Minimum & Maximum & Minimum & Maximum & Minimum & Maximum & Minimum & Maximum \\
\hline 1 & $6 \cdot 6$ & 470 & 1249 & 393 & 827 & 68 & 175 & 942 & 2114 \\
\hline 2 & 10 & 470 & 880 & 391 & 669 & 61 & 130 & 968 & 1617 \\
\hline 3 & $11 \cdot 3$ & 261 & 731 & 231 & 734 & 58 & 144 & 550 & 1600 \\
\hline 4 & 8.6 & 502 & 1151 & 117 & 675 & 80 & 156 & 915 & 1872 \\
\hline 5 & 26 & 530 & 1883 & 412 & 1346 & 48 & 166 & 1151 & 3396 \\
\hline 6 & $10 \cdot 3$ & 429 & 979 & 303 & 699 & 64 & 145 & 900 & 1617 \\
\hline 7 & $10 \cdot 4$ & 307 & 869 & 433 & 729 & 54 & 142 & 828 & 1582 \\
\hline 8 & $26 \cdot 7$ & 453 & 1582 & 340 & 1087 & 52 & 324 & 986 & 2600 \\
\hline 9 & 18 & 406 & 948 & 351 & 824 & 58 & 175 & 830 & 1760 \\
\hline 10 & $14 \cdot 7$ & 348 & 895 & 356 & 882 & 68 & 219 & 812 & 1995 \\
\hline 11 & $13 \cdot 2$ & 400 & 943 & 380 & 793 & 73 & 140 & 919 & 1832 \\
\hline 12 & $19 \cdot 3$ & 449 & 1561 & 301 & 1136 & 50 & 270 & 800 & 2967 \\
\hline
\end{tabular}

TABLE II - Variations in budget allocation per patient (£) among fundholding practices

\begin{tabular}{|c|c|c|c|c|c|c|c|c|c|c|c|c|}
\hline \multirow[b]{2}{*}{ Region } & \multicolumn{3}{|c|}{ Hospital services } & \multicolumn{3}{|c|}{ Prescribing } & \multicolumn{3}{|c|}{ Staff } & \multicolumn{3}{|c|}{ Total budget } \\
\hline & Minimum & Maximum & Mean (SD) & Minimum & Maximum & Mean $(\mathrm{SD})$ & Minimum & Maximum & Mean (SD) & Minimum & Maximum & Mean (SD) \\
\hline 1 & 45 & 70 & $52(15)$ & 35 & 58 & $47(9)$ & 6 & 13 & $9(3)$ & 86 & 138 & $114(16)$ \\
\hline 2 & 43 & 62 & $51(5)$ & 33 & 58 & $44(8)$ & 5 & 12 & $8(2)$ & 84 & 128 & $103(12)$ \\
\hline 3 & 35 & 60 & 51 (7) & 35 & 56 & 44 (7) & 7 & 11 & $9(1)$ & 79 & 124 & 104 (11) \\
\hline 4 & 48 & 99 & $60(16)$ & 12 & 52 & 34 (11) & 5 & 13 & $10(2)$ & 82 & 161 & $104(20)$ \\
\hline 5 & 30 & 104 & $72(16)$ & 19 & 66 & $48(10)$ & 3 & 10 & $8(2)$ & 52 & 176 & $129(22)$ \\
\hline 6 & 42 & 85 & $57(14)$ & 26 & 60 & $40(9)$ & 5 & 11 & $8(2)$ & 78 & 135 & $105(18)$ \\
\hline 7 & 33 & 87 & $54(12)$ & 38 & 63 & 49 (7) & 5 & 10 & $8(1)$ & 85 & 147 & $110(15)$ \\
\hline 8 & 43 & 97 & $63(12)$ & 36 & 62 & 49 (7) & 4 & 20 & $10(3)$ & 100 & 159 & $121(16)$ \\
\hline 9 & 41 & 79 & $59(10)$ & 36 & 67 & 48 (7) & 6 & 11 & $8(1)$ & 87 & 147 & $115(13)$ \\
\hline 10 & 35 & 60 & $46(8)$ & 29 & 52 & $42(5)$ & 7 & 12 & $9(1)$ & 74 & 113 & $96(11)$ \\
\hline 11 & 42 & 68 & $56(7)$ & 41 & 62 & $50(6)$ & 6 & 11 & $8(1)$ & 94 & 134 & $114(12)$ \\
\hline 12 & 41 & 77 & $56(8)$ & 29 & 55 & 43 (7) & 5 & 10 & $8(1)$ & 82 & 133 & $106(13)$ \\
\hline
\end{tabular}


practices by a simple correlation analysis. A positive correlation $(r=0.25, \mathrm{p}<0.001)$ was found between hospital costs and prescribing costs but neither of these were correlated with staffing costs.

On the other hand, if organisation of the practice determined cost there might be economies of scale or opportunities for substituting one form of provision for another. In fact, the analysis showed that the list size was negatively related to the total budget per patient $(r=-0.21, \mathrm{p}<0.001)$ as well as to per spending on drugs $(r=-0.22, \mathrm{p}<0.001)$ and to staff $(r=-0 \cdot 2$, $\mathrm{p}<0.001)$ per patient. Interestingly, there was no significant relation between list size and spending per patient on hospital services, although this is the largest element in the total budget. So it would seem that while indeed there are some economies of scale, they do not apply across all three elements of the budget.

Differences between the regions might provide further clues about the respective roles of patient population and practice characteristics in explaining variations in spending. Table II shows that differences in regional spending on hospital services do exist. Mean regional spending ranges from $£ 46$ to $£ 72$ per head for hospital services, from $£ 33$ to $£ 49$ for prescribing, and from $£ 8$ to $£ 10$ for staff. So factors specific to regions may be important. There are enough cases to ensure that the differences are not due to sampling error. As we wanted to avoid identifying regions we could not pursue this point further-for example, by relating regional spending to indicators of morbidity found in the general household survey. Certainly such an exercise would be worth while.

\section{Conclusions}

Fundholding has created a set of puzzles. Yet, paradoxically, the same exercise that has raised the questions has also provided the means for answering them. To determine the budgets of the fundholding practices the regions have had to collect an unprecedented amount of information about general practice; data that will be greatly increased when the second wave of fundholders come through.

The information collected would allow the questions we have identified about the relative importance of rates of activity and hospital prices in determining budgets and about the contribution of age structure and morbidity in explaining variations to be examined. It will, however, need Department of Health support to bring together the information held among the regions and to provide the funding required for an analysis. And at present there is no sign of such an initiative. In its absence, there will inevitably be a reversion to the traditional NHS pattern: great expenditure on collecting information that is sub- sequently ignored because of the failure to invest in analysis.

The importance of achieving a greater understanding of the variations stems from the fact that the present system of allocation will clearly have to be changed over the next few years. The fundholding initiative has given visibility to differences in the per patient funding of health care that are almost as striking as the differences in the financing of health authorities that led to the introduction of a new formula for allocating resources in the 1970s: the RAWP formula. ${ }^{6}$ Given the sums involved and the likely increase in the transfer of resources to general practitioners if fundholding spreads, there will be an inevitable demand for equity in the allocation of money according to need, rather than to accident of history, which is what happened in the hospital sector.

Moreover, general practitioners themselves may well reinforce such a demand. If fundholder A gets twice as much for each of his or her patients than does fundholder B, this may cause ill feeling - fundholder A could be at a competitive advantage if his or her greater budget allows more or better services to be bought. A sense of bewilderment or grievance may be further compounded because of present uncertainty about how budgets will be revised in future. If, for example, a fundholder negotiates cheaper prices, will the budget be cut in future years or can the money saved be used to buy extra services? There are no clear rules and therefore no clear incentives.

An analysis of practice patterns and populations might show that there is no injustice in the existing inequalities. This, however, cannot be taken for granted and needs to be tested against the data. It seems likely that we will need to move towards a system of per head payments adjusted for the patients' age. But any such move should, surely, be based on an informed analysis rather than a sudden realisation that present methods are unsustainable.

We thank Nick Rigillo and Victor E van Reijswoud for statistical analysis. The study is part of a project funded by the Economic and Social Research Council, grant No G00232419.

\footnotetext{
1 Wilkin D, Dornan C. General practitioner referrals to hospital. Manchester Centre for Primary Care Research, University of Manchester, 1990. 2 Roland M. General practitioner referral rates. BMF 1988;297:437-8. 3 Crombie DL, Fleming DM. General practitioner referrals to hospital: the financial implications of variability. Health Trends 1988;20:53-6.

4 Wilkin D, Hallam L, Leavey R, Metcalfe D. Anatomy of urban general practice. London: Tavistock, 1987

5 Secretary of State for Health and Chief Secretary to the Treasury. Department of Health and Office of Population Censuses and Surveys: departmental report. London: HMSO, 1991. (Cmnd 1513.)

6 Buxton M, Klein R. Allocating health resources: a commentary on the report of the Resource Allocation Working Party. London: HMSO, 1978.
}

(Accepted 4 fune 1991)

\section{MIRROR OF MEDICINE}

Although the fournal rejected many advertisements, most of these were for medical appointments deemed to be offered on unsatisfactory conditions or at inadequate salaries. Numerous products of dubious value continued to appear. In 1910 the National British Women's Temperance Association called for the fournal to stop taking advertising for so called medicated wines such as Wincarnis, which the NBWTA described as "one of the great class of quack secret remedies which are ruining the Medical Profession and the public." In this instance, urged on by the Annual Representative Meeting, the fournal excluded advertising from Wincarnis and also for Hall's wine, a product which contained cocaine. The Association again reviewed its policy on food and drug advertising and decided that those advertisements containing false statements, and those advertised elsewhere in "a misleading or otherwise objectionable manner," should be rejected. Elliston, who examined how the new policy would affect fournal revenue, found that advertisements for alcoholic drinks, including diabetic whisky, and food preparations would remain acceptable. Certain items, including
Bragg's Charcoal Biscuits, Kond's Euonymised Cocoa, and Sanatogen, would have to be excluded if they were advertised, as Sanatogen was, in the lay press.

Although most of the advertisements refused by the fournal continued to be for medical appointments, the costliest rejections were of foods and drugs, for example, Junora Wine and Sandow Cocoa, the refusal of which, in 1911 , meant lost revenue of $£ 33216 \mathrm{~s}$. But even though the fournal was monitoring its advertising of food and drug preparations, its policy was not above reproach. In short, as a periodical intent on exposing the proprietary medicine trade and the newspapers profiting from it, the fournal was in a vulnerable position.

From Mirror of Medicine: A History of the BMF by P W J Bartrip. Published jointly by the $B M \mathcal{F}$ and Oxford University Press; BMA members' price UK $£ 29$, overseas $£ 33$, including postage. Obtainable from the Publishing Manager,

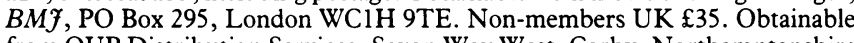
from OUP Distribution Services, Saxon Way West, Corby, Northamptonshire NN18 9ES. 